\title{
Die griechische Editio princeps des Galenos (1525), ihre Entstehung und ihre Wirkung*
}

\author{
Von Nikolaus Mani, Basel
}

Zehn Jahre nach dem Tode des berühmten Druckers, Herausgebers und Humanisten Aldo Manuzio ${ }^{1}$, erschien im Jahre 1525 aus der aldinischen Offizin in Venedig das Gesamtwerk Galẹs in griechischer Sprache. Als Druckherr zeichnete Andrea Torresano aus Asola ${ }^{2}$ (Andreas Asulanus), der Schwiegervater des Aldus. Nach dem Tode des Aldus, der seine noch unmündigen Kinder der Obhut seines Schwiegervaters anvertraut hatte, war die Leitung der aldinischen Druckerei an Asulanus übergegangen. Die Textgestaltung des griechischen Galen überwachte der Arzt und $\mathrm{Hu}$ manist Giovanni Battista Oppizzoni ${ }^{3}$ aus Pavia.

* Der vorliegende Aufsatz bildet einen Ausschnitt aus einer Arbeit über die philologischhumanistische Richtung in der Medizin des 16. Jahrhunderts, die mir im Rahmen eines Stipendiums der Alexander-von-Humboldt-Stiftung an den medizinhistorischen Instituten der Universitäten Bonn und Frankfurt am Main ermöglicht wurde. Mein herzlicher Dank gebührt der Alexander-von-Humboldt-Stiftung sowie den Herren Prof. Dr. J. Steudel, Direktor des Medizinhistorischen Institutes der Universität Bonn, und Prof. Dr. W. Artelt, Direktor des Senckenbergischen Institutes für Geschichte der Medizin der Universität Frankfurt am Main, die meiner Arbeit eine stete und wertvolle Hilfe angedeihen ließen. Bester Dank sei auch Herrn Dr. med. G. Manv von der SenckenbergBibliothek Frankfurt am Main für die bibliothekarische Betreuung und Herrn Dr. phil. K. OHLY von der Universitätsbibliothek Frankfurt am Main für viele wertvolle bibliographische Hinweise über Inkunabel- und Frühdrucke, ausgesprochen.

${ }^{1}$ Ant. Aug. Renouard, Annales de l'imprimerie des Aldes, $3^{\mathrm{e}}$ éd., Paris 1834 (= Renouard 1834). A. Finmin-Didot, Alde Manuce et l'hellénisme à Venise, Paris 1875 (= FirminDidot 1875). J. SснücK, Aldus Manutius und seine Zeitgenossen in Italien und Deutschland, Berlin 1862. E. Goldsmid, A bibliographical Sketch of the Aldine Press at Venice, part I-III, Edinburgh 1887.

2 D. Bernoni, Dei Torresani, Blado e Ragazzoni, Milano 1890, S. 3, 5, 9, 77.

${ }^{3} \mathrm{Zu}$ Giovanni Battista Oppizzoni oder Oppizzone (lateinisch Opizo) vgl. H. Diels, $A b h$. Preuß. Akad. Wiss., philos.-hist. Kl. 1912, 11, Anm. 1; J. Mewald, Die Editio princeps von Galenos in Hippocratis de natura hominis, Sber. kgl. Preuß. Akad. Wiss., philos.-hist. Kl. XXXIX (1912) 892-903 (= Mewaldt 1912); Corpus Medicorum Graecorum V, 9 (1914) 1, praefatio, S. XVIII; E. WENKEBaCh, Beiträge zur Textgeschichte der Epidemienkommentare Galens, in Abh. Preuß. Akad. Wiss., philos.-hist. Kl. 1927, Nr. 4, S. 3, 25 ff.; E. Wenkebach, John Clement, ein englischer Humanist und Arzt des 16. Jahrhunderts, in Stud. Gesch. Med. 1925, Leipzig, Heft 14, S. 14 ff. (Gründliche Darstellung, die einen ausgezeichneten Einblick in die philologisch-humanistische Medizin der Renaissance gibt.) 
Die Galenaldina, eines der umfangreichsten in der aldinischen Offizin entstandenen Druckwerke, ist in zweifacher Beziehung bedeutungsvoll. Einmal steht sie am Beginn der humanistischen Bemühungen um die Edition des griechischen Galen-Textes. Bis tief ins 19. Jahrhundert hinein blieb die Galenaldina die hauptsächlichste Grundlage und Quelle für die griechischen Druckausgaben Galens. Die Editio Basileensis (1538), die Charteriana im 17. Jahrhundert und die KüHNsche Ausgabe im 19. Jahrhundert fließen, was den griechischen Text betrifft, direkt aus der Aldina ${ }^{4}$. Die Galenaldina ist ein weithin sichtbares Zeugnis der unablässigen, von $\mathrm{Hu}$ manisten und Humanistenärzten geleisteten Arbeit, den Galenos in seiner ursprünglichen griechischen Fassung erstehen zu lassen. Erst mit der Editio aldina erfolgte der entscheidende humanistische Einbruch in die galenische Literatur und Tradition. Die humanistische Grundforderung: ad fontes, zu den unmittelbaren antiken Quellen, wurde mit der Ausgabe des griechischen Galen verwirklicht ${ }^{5}$.

${ }^{4}$ E. Wenkebach, Pseudogalenische Kommentare zu den Epidemien des Hippokrates, in Abh. Preuß. Akad. Wiss., philos.-hist. Kl. 1917, Nr. 1 (= Wenkebach 1917), S. 5: «Die Basileensis ist bekanntlich wie die Ausgabe von Chartier und die von Kühn ohne neues handschriftliches Material zustande gekommen.»-J. Westenberger, Galeni qui fertur de qualitatibus incorporeis libellus, Diss. Marburg 1906, S. XIII, sagt vom Text dieser Schrift: «... Ac ne forte posteriores aliis codicibus usos esse existimes, plane ex Aldina dependet b (= Ed. Basileensis), ex qua ut c (= ED. Chartier) ad verbum fere expressa est, ita Kuehnius ex c suum textum descripsit ...» - Für den galenischen Kommentar zu Hippocratis de natura hominis sagt Mewaldt 1912, S. 893: «Denn der Editor princeps des Galenos hat die Fassung des Textes bis zu dem letzten Herausgeber (KüHN) in maßgebenster Weise beeinflußt.» - Für die Schriften Galens Über die eigenen Bücher vgl. Marquart, Müller, Helmreich, Galeni scripta minora, Vol. II, Lipsiae MDCCCXCI, S. LVI: «Ex Aldina fluxerunt ceterae editiones ...» - Für die Schrift Galens De usu partium bemerkt G. Helmreich in der Praefatio zu der griechischen Ausgabe dieses Werkes, 1907, Vol. I, Leipzig (Teubner), S. XV: «Nemo igitur post eos qui editionem principem curaverunt codicem ad textum restituendum adhibuit. Unde factum est, ut opus Galenianum hodie quoque falso inscribatur ...»- G. KAIBEL, Cl. Galeni protreptici quae supersunt, Berlin 1894, bemerkt zum Text dieser Schrift, S. VI: «Basileensis (1538) ad litteram fere ex Aldina expressa paucis admodum pusillis erroribus correctis ...» - I. MüLLER, Galeni libellus quo demonstratur optimum medicum eundem esse philosophum, Erlangen 1875, S. 10, sagt zum Text der Basileensis: "... tota ex Aldina pendet ...» - Zur Schrift De sanitate tuenda sagt K. Kосн (Corpus Medicorum Graecorum V, 4, 2, praefatio, S. XXII): «Quartam partem editionis Basileensis curavit Joachim Camerarius, totus ab editione principe pendens ...»; G. HeLmReich bemerkt zur Schrift De alimentorum facultatibus (Corpus Medicorum Graecorum V, 4, 2, praefatio, S. XLI): «Inter Editiones Aldina sola digna est, cuius ratio habeatur, Basileensis paucissimis ac levissimis mendis sublatis ceteroquin Aldinam refert ...» 
Weiterhin wurde die Galenaldina von hervorragender Wichtigkeit für die neue literarische Gestaltung des Galen-Textes, die seit dem Ende des 15. Jahrhunderts einsetzte und nach Zielsetzung und Methode aus der humanistischen Bewegung entsprang. Die Editio aldina bildete nämlich als riesiger, standardisierter und allgemein zugänglicher ${ }^{5 \mathrm{a}}$ "Codex vulgatus» die Übersetzungsvorlage für die von den Humanisten angestrebte Latinisierung des galenischen Gesamtwerkes. Seit dem Erscheinen des griechischen Galen strömte denn auch eine Flut lateinischer Galen-Übersetzungen auf den medizinischen Büchermarkt.

Die Galenaldina wurde zu einem neuen Ansatzpunkt in der Galen-Tradition. Bisher hatte man Galen aus zwei Quellen geschöpft: Einmal aus lateinischen Übersetzungen arabischer Galen-Texte ${ }^{6}$, dann aus griechischlateinischen Übersetzungen, die auf das Mittelalter (12. bis 14. Jahrhundert) zurückgingen ${ }^{7}$. Die frühen, griechisch-lateinischen Galen-Übersetzer

${ }^{5}$ Jacobus Sylvius, der bedeutende Pariser Galenist, schrieb in seinem Werk De febribus commentarius Parisiis (apud Petrum Drouart) 1554, S. 3, von den «fontes purissimi» die in Galen und Hippokrates gelegen seien. - Michael Servet schrieb im Vorwort zu seinem Buche Syruporum universa ratio ad Galeni censuram diligenter expolita, Paris (Simon Colinaeus) 1537: «Galenus renascitur vero felici nostro seculo, ut seipsum turpius deformatum in pristinum candorem restituens illustret ... zit. nach J.F. PAYNE, Harvey and Galen, London 1897, S. 21; vgl. dazu auch: СH. D. O'MaLley, Michael Servetus, London/Philadelphia 1953, S. 60.

5a Die Wichtigkeit des Buchdruckes für die Verbreitung wissenschaftlichen Gedankengutes liegt vor allem darin, daß mit den Druckausgaben erstmals ein bestimmter Text in einer größeren Anzahl identischer und damit vergleichbarer Exemplare herauskam. Vgl. dazu G. Sarton, The Appreciation of Ancient and Medieval Science During the Renaissance, Philadelphia 1955, S. 167.

${ }^{6}$ G. Sarton, Galen of Pergamon, Lawrence (Kansas) 1954, S. 89; G. SARton, The Appreciation of Ancient and Medieval Science During the Renaissance, Philadelphia 1955 (= Sarton 1955), S. 19; G. SARton, Introduction to the History of Science, Vol. II, 1, Baltimore 1931, S. 65, 342 (= Übersetzungen galenischer Texte durch Gerhard von CreMONA), 344 (= Übersetzungen galenischer arabischer Texte durch Marcus Toledanus); H. Schipperges, Die frühen Übersetzer der arabischen Medizin in chronologischer Sicht, in Sudhoffs Arch. Gesch. Med. 39 (1955) 53-93 (Grundlegende Übersicht und systematische Gliederung des Stoffes anhand der bisherigen Sekundärliteratur) GERHARD voN Cremona, S. 82, Marcus Toledanus, S. 83.

${ }^{7}$ Auch im Mittelalter gab es immer vereinzelte Kenner der griechischen Sprache im westlichen Kulturkreis. Diese frühen Galen-Übersetzer, wie etwa Burgundio von Pisa (vgl. Anm. 8), der im 12. Jahrhundert wirkte, stützten sich auf ein beträchtlich älteres handschriftliches Material als den Humanisten im allgemeinen zugänglich war, die meist aus Handschriften des 15. Jahrhunderts oder aus noch jüngeren Abschriften derselben edierten und übersetzten. 
waren Burgundio von Pisa (12. Jahrhundert) ${ }^{8}$, Wilhelm von Moerbeke (13. Jahrhundert) ${ }^{9}$, Pietro D'Abano (13./14. Jahrhundert) ${ }^{10}$, und NicCOLò DA REGGio (14. Jahrhundert) ${ }^{11}$ aus Kalabrien. Diese mittelalterlichen Übertragungen geben teilweise einen viel getreueren Galen-Text wieder als die neueren humanistischen Übersetzungen, da sie auf einem beträchtlich älteren handschriftlichem Material fußen und wortgetreu «de vervo ad verbum » übersetzt wurden ${ }^{12}$. Im Druck erschienen ein Teil dieser mittelalterlichen griechisch-lateinischen Übersetzungen in der Galen-Inkunabel des Jahres $1490^{13}$, welche in Venedig bei Philippus Pintius de Caneto heraus-

${ }^{8}$ G. SARTon, Introduction to the History of Science, II, 1 (1931), S. 348 (mit Sekundärliteratur); L. Thonndike und P. Kibre, A Catalogue of Incipits of Medieval Scientific Writings in Latin (Medieval Acad. of America, Cambridge [Mass.] 1937, S. 199, 200, 211, $474,552,581,584,694)$. Burgundio von Pisa übersetzte unter anderem De febribus, De ingenio sanitatis (= Methodus medendi).

${ }^{9}$ G. SARTon, Introduction to the History of Science, II, 2 (1931) S. 829-31, S. 830 (= Moerbekes Übersetzung der galenischen Schrift De alimentis); H. Schöne, Ein Palimpsestblatt des Galen aus Bobbio, Sber. kgl. Preuß. Akad. Wiss., philos.-hist. Kl. XXI (1902) 442-7 (Besprechung der von MoErBeke gemachten Übersetzung der Schrift Peri ton en tais trophais dynameon und ihr Verhältnis zum alten griechischen Text aus dem VI. Jahrhundert.

${ }^{10}$ L. Thorndike, A History of Magic and Experimental Science, Vol. II, New York 1929, S. 874-947 (Biographie und Werke Pietro D'Abanos), S. 915-6 = Sekundärliteratur, S. 918-9 = Galen-Übersetzungen; L. Nовротн, Zur Bio-Bibliographie und Wissenschaftslehre des Pietro d'Abano, in Kyklos III, S. 292-353; L. ThonNdIKe, Translations of Works of Galen from the Greek by Peter of Abano, in Isis XXXIII (1942) 649-53; L. ThorNdiKe, in Bull. Hist. Med. XV (1944) 201-19; G. SARTon, Introduction to the History of Science III, 1 (1947), S. 439-46 (mit Sekundärliteratur).

${ }^{11}$ G. SARToN, Introduction to the History of Science III, 1 (1947), S. 446-8. Hier werden die Galen-Übersetzungen des Niccolò DA REgGio angeführt und teilweise auch die frühen Druckausgaben derselben. Vgl. vor allem H. SснӧNE, Galenus de partibus artis medicative (Festschrift Universität Greifswald), Greifswald 1911 (= SснӧNE 1911). Hier finden sich die Druckausgaben des Niccolò DA REgGio in einer frühen Galen-Juntina des Jahres 1528 angeführt, S. $6 \mathrm{ff}$.

${ }^{12}$ Im Prolog zu seiner griechisch-lateinischen Übersetzung der galenischen Schrift De utilitate particularum (= De usu partium) schreibt Niccolò DA Reggio (Schöne, 1911, S. 10): «... ipsum librum transtuli vobis fideliter et de verbo ad verbum, nihil addens minuens vel permutans.» Aus diesem Grunde benutzte schon Cornarius zur Emendation des Galen-Textes die Übersetzungen des Niccolò DA Reggio, vgl. R. Noll, Galeni

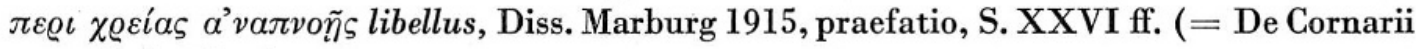
emendationibus).

${ }^{13}$ Für die bibliographische Beschreibung der Galen-Inkunabel des Jahres 1490 siehe bei Hain, Repert. bibl. Nr. 7427; F.N.L. Poynter, A Catalogue of Incunabula of the Wellcome Historical Medical Library, Oxford 1954, Nr. 244 (= Poynter 1954); A.C. KLebs, 
kam, sowie in den Frühdrucken der Opera omnia Galens, die in Venedig und Pavia innerhalb der ersten drei Jahrzehnte des 16 . Jahrhunderts erschienen ${ }^{14}$. $\mathrm{Zu}$ derselben Zeit, da sich einerseits der «Galenus mediaevalis» in Inkunabel- und Frühdrucken als Gesamtopus verdichtete, und da anderseits in Inkunabeln und Postinkunabeln einzelne neuere humanistische GalenÜbersetzungen, die «translationes novae» erschienen ${ }^{15}$, kam aus der aldini-

Incunabula scientifica et medica, in Osiris IV (1938) 147. Kurze Besprechung auch bei G. Sarton 1955, S. 20, 187, Anm. 54. Der Drucker war Philippus Pintius von Caneto (vgl. Catalogue of Books Printed in the $X V^{\text {th }}$ Century Now in the British Museum, part V [Venice] London 1924, Introduction, S. XLIV), als Herausgeber zeichnete der Arzt Diomedes Bonardus aus Brescia. In der Einleitung zu den Opera omnia Galens bemerkt Diomedes Bonardus (Fol. 6v der unpaginierten Inkunabel): «... hortatus sum non nullos suscipere onus imprimendi Galieni libros: hac de causa tantum motus: ut quod ex fonte haberi possit: ex eius rivulo minime suscipiatur: sed spe tali hucusque frustratus ego Diomedes bonardus physicus brixiensis omni studio summaque diligentia percurrens Galieni libros: qui ob transcriptorum ignorantiam adeo corrupti ac mendosi reperiebantur ...»W Wenn auch die Intention und Phraseologie des Diomedes - will er doch den Galen ex fonte habere, und ad fontes war das humanistische Schlagwort - eine durchaus humanistische war, so sind doch der größte Teil der Galen-Übersetzungen, die er veröffentlichte, mittelalterliche Übertragungen. Einige Inzipits und Explizits aus den Werken der Galen-Inkunabel mögen die doppelte Quelle derselben, einerseits die arabolateinische, anderseits die gräko-lateinische Tradition, beleuchten. «Incipit liber Ga. de iuvamento pulsus quem transtulit Joannes filius Ysaac de greco in arabicum: et Marcus toletanus de arabico in latinum» (= arabo-lateinische Überlieferung). - «Explicit liber Galieni de colera nigra quem petrus padubanensis (= PiETro D'ABANo) de greco translatavit in latinum. » - «Explicit liber Galieni de notitia tumorum preter naturam secundum translationem Nicolai de regio de calabria de greco in latinum.» - «Explicit liber Galieni de virtute alimentorum translatus a fratre Guielmo de morbeka (WILHELM von MoerBEKE) ordinis predicatorum archiepiscopo corinthiensi ex greco in latinum » (= Gräkolateinische Tradition). Während in den zwei Bänden der Galen-Inkunabel WILHELM voN Moerbeke als der Übersetzer eines Galen-Werkes und Pietro D'Abano als der Übersetzer zweier Galen-Werke namentlich genannt wird, steht der Übersetzername des «Nicolaus de regio de calabria» am Anfang oder Ende von rund zwanzig Galen-Werken in der Inkunabel von 1490.

${ }^{14} \mathrm{Zu}$ den in Pavia erscheinenden Opera omnia Galens (1515/16) vgl. Panzer, Annal. typogr. VII, S. 497, Nr. 21; vgl. dazu auch SARTON, Introduction to the History of Science III, 1 (1947) S. 446-8, und R. NoLL, l.c., 1915, S. XIX ff. Zu den frühen Galen-Juntinen (Venedig 1522 und 1528) vgl. Panzer, Vol. VIII, S. 474, Nr. 1135, und Vol. VIII, S. 508, Nr. 1453; Zur Juntina 1528 vgl. Schöne 1911, S. 6 ff. Vgl. auch L. Choulant, Handbuch der Bücherkunde für die ältere Medizin, Leipzig 184.1, Galen, S. $98 \mathrm{ff}$.

${ }^{15}$ Giongio VALLA, einer der ersten Philologenärzte gräko-humanistischer Richtung, übersetzte an Galen-Schriften: De optima corporis nostri confirmatione, De bono habitu, De inaequali distemperantia, De praesagitura und andere (KLEBS, Osiris IV, S. 330). Zu 
schen Presse der «griechische Galen » auf den Markt. Die Galenaldina verkörperte einen dritten Überlieferungsmodus. Sie war ein reines Produkt der philhellenischen Bewegung und ganz anderer Genese als die eben betrachteten mediävalen Übersetzungen des Galen. Ihre Wurzeln reichen ins 15. Jahrhundert, in das italienische Quattrocento hinein. Damals erfüllten sich die Bedingungen, welche die Edition dieses großen Galen-Werkes ermöglichten: Die Überzeugung von der Superiorität des antiken griechischen Kulturgutes ${ }^{16}$, die Kenntnis der griechischen Sprache ${ }^{17}$, der Erwerb und

Giongio Valla vgl. J.L. Heiberg, Beiträge zur Geschichte Georg Vallas, in XVI. Beih. Zbl. Bibliothekswesen (1896) (= Heiberg 1896). Francesco Filelfo übersetzte Galens Introductorium ad medicinam (KLEBS, Osiris IV, S. 141). In einem Frühdruck der Arti-

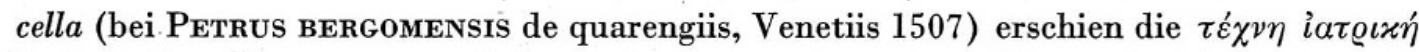
in doppelter Übersetzung: «In hoc volumine continentur ... liber techni Galieni secundum antiquam translationem et novam pariter elegantissimam. » Unter den «translationes novae» verstand man zu dieser Zeit die neuen griechisch-lateinischen Übersetzungen, die die Humanisten herausbrachten. Im Textteil heißt der Titel der galenischen Schrift: Galeni pergameni Ars parva interprete Laurentiano florentino viro litteratissimo. Im Titel der Galen-Juntina 1528 wird angegeben, daß neben «alten Übersetzungen», die den Grundstock dieser Ausgabe bildeten, auch die modernen Übertragungen aufgenommen seien: «... omnes tam veteres quam novas interpretationes continet ...» (PANZER, Vol. VIII, S. 508, Nr. 1453).

16 Aldus Manutius gab einem weit verbreiteten Gefühl Ausdruck, als er in der Vorrede zu seiner Editio princeps der Aristophanes schrieb: «Perbeati illi mihi videntur clari ... qui hoc tempore ... graece discunt ... Facillime, graecis literis adiutricibus, omnium laudatarum artium procreatricem philosophiam callebunt, nec medicinam minus ...» (zit. nach B. BotfIELd, Praefationes et epistolae editionibus principibus auctorum veterum praepositae, Cantabrigiae 1861 (= Botfield 1861), S. 218. AleXander Hegrus, der einflußreiche Leiter der Stiftsschulen von Emmerich und Deventer, äußerte sich über den Wert des Griechischen:

«Quisquis Grammaticam vis discere, discito Graece

Ut recte scribas, non prave, discito Graece

Artibus et medicis qui aptus, discito Graece.»

(zit. nach P. Pendzig, Die Anfänge der griechischen Studien in den gelehrten Schulen Westdeutschlands, in Neue Jb. klass. Altert. Pädag. 46 (1920) 164-88, S. 171-2. BernarDUs NerLIUs begleitete die Erstausgabe des griechischen Homer (Florenz 1488) mit folgenden, an Pietro de'Medici gerichteten Worten: «... Homerum ut vetustate primum, ita etiam divino quodam ingenio summum poetam ac litterarum fontem elegi .... (zit. nach Botfield 1861, S. 181. Die hohe Bedeutung der griechischen Medizin hob in eindrücklichen, auch für die späteren Humanistenärzte verpflichtenden Worten Nicolaus LeONicenus in seinem Buche De Plinii et plurium aliorum medicorum erroribus, Ferrara (Joannes Maciochius) 1509, fol. 74r: «Quare diligentius considerantibus doctrina Avicennae cum tot expositoribus, qui partim alii ab aliis, partim iidem a se ipsis in variis locis discordant, chaos quoddam videri possit, qua confusionis obscuritate nihil possit esse 
die Sammlung griechischer Manuskripte und die Erfindung und Einführung des griechischen Buchdruckes ${ }^{18}$.

Byzantiner aller Bildungsgrade, vom Abschreiber bis zum hohen geistlichen Würdenträger, kamen vor und nach dem Falle Konstantinopels nach Italien ${ }^{19}$, und italienische Humanisten hielten sich kürzere oder längere

humanae vitae periculosius. Nos sane ad hanc amovendam, atque extirpandam et nostrae aetatis hominibus lucem aliquam veritatis aperiendam, partim librorum Galeni medicorum principis translationibus partim in eosdem commentationibus, die noctuque laboramus ... V Vl. auch H.O. TAYLOR, Thought and Expression in the $16^{\text {th }}$ Century, Vol. I, New York 1920, S. 36 ff. Siehe auch Anm. 18 unter A. Bernard.

17 J.E. SANDYs, A History of Classical Scholarship, Vol. II, Cambridge 1908 (grundlegendes Werk mit reicher Sekundärliteratur) (= Sandys 1908); O. KLUGE, Die griechischen Studien in Renaissance und Humanismus, in Z. Gesch. Erziehung Unterricht 24 (1934) 1-54; W. Kroll, Geschichte der klassischen Philologie, 1908 (Sammlung Göschen 367); F. PAUlsen, Geschichte des gelehrten Unterrichtes an den deutschen Schulen und Universitäten, 1. Bd. 3. Auflage, Leipzig 1919, S. 70 ff.; Georg Voigt, Die Wiederbelebung des classischen Alterthums oder das erste Jahrhundert des Humanismus, 2. Bd. 3. Auflage, Berlin 1893, S. 101 ff., S. 160 ff. (= Voigt 1893); L. GEIGER, Renaissance und Humanismus in Italien und Deutschland, Berlin 1882, S. 114, 168, 196, 323; P.S. Allen, The Age of Erasmus, Oxford 1914, S. 11, 16, 30, 134; A. ВоЕскн, Encyklopädie und Methodologie der philologischen Wissenschaften, Leipzig 1886, S. 300-9; E. Legrand, Bibliographie hellénique ou description raisonnée des ouvrages publiés en grec par des grecs au XVe et XVI ${ }^{e}$ siècles, T. I (1885), T. II (1885) T. III (1903) Paris (= Legrand I, II, III).

${ }^{18}$ Für die Hauptquelle griechischer Druckwerke am Anfang des 16. Jahrhunderts, die aldinische Offizin, s. Literatur bei Anm. 1; Firmin-Didot 1875, S. 587 ff.; Sandys 1908, S. 95 ff.; Botfield 1861, passim; V. Scholderer, Printers and Readers in Italy in the $15^{\text {th }}$ Century (Ann. Ital. Lect. Brit. Acad. XXXV [1949], S. 8, 9, 16; Catalogue of Books Printed in the $X V^{\text {th }}$ Century Now in the Brit. Museum, part VII, London 1935, Introduction, S. XV ff.; C. CAStellani, La stampa in Venezia dalla sua origine alla morte di Aldo Manuzio seniore, Venezia 1889, S. 29, Anm. 4; H.F. Brown, The Venetian Printing Press, London 1891; A. Bernard, Les Estienne et les types grecs de Francois I rer, Paris 1856, S. 11, König Franz I. von Frankreich umschrieb bei der Ernennung eines königlichgriechischen Druckers im Jahre 1538 die Bedeutung der griechischen Wissenschaften mit folgenden Worten: «... Nam a viris literatis accepimus, ut e fontibus rivulos, ita e grecis scriptoribus artes, historiarum cognitionem, morum integritatem, recte vivendi praecepta, ac omnem prope humanitatem ad nos derivari ...»

19 Vgl. vor allem das grundlegende Werk von E. Legrand, Bibliographie hellénique, l.c.; Sandys 1908, S. 59 ff., S. 74 ff.; Voigt 1893; Firmin-Didot 1875, S. 147, 456, 460; Zu Bessarion vgl. L. Mohler, Kardinal Bessarion als Theologe, Humanist und Staatsmann, 1. Bd. (= Darstellung) in Quellen u. Forsch. Gebiet d. Gesch., Vol. XX, 1923; zu Konstantin LASKaris, dessen griechische Grammatik als erstgedrucktes griechisches Buch herauskam (Mailand 1476), vgl. H. RABE, Konstantin Laskaris, in Zbl. Bibliothekswesen 45 (1928) 1-7. 
Zeit in Byzanz auf, um griechisches Geistesleben kennenzulernen ${ }^{20}$. So wurde die griechische Sprache nach Italien verpflanzt. Papst Nikolaus V., ein leidenschaftlicher Sammler griechischer Handschriften, verfolgte den Plan, die Werke griechischer Autoren zu latinisieren. Für ihn übersetzten die Byzantiner Theodor Gaza, Georgios Trapezuntios und eine ganze Reihe italienischer Humanisten ${ }^{21}$. Die griechischen Ärzte wurden von dieser ersten Übersetzungswelle nur unwesentlich erfaßt ${ }^{22}$.

Von größter Bedeutung für die neue Rezeption der griechischen Medizin, die mit voller Kraft erst im 16. Jahrhundert einsetzte, wurde der Umstand, daß in den neugegründeten öffentlichen und privaten Bibliotheken ein reicher Schatz an griechischen Kodizes angelegt wurde, der einen weiten Bereich antiker Literatur umspannte und unter andern auch die griechischen und byzantinischen Ärzteautoren enthielt ${ }^{23}$.

In der Vaticana befanden sich zur Zeit Nikolaus des V., um die Mitte des XV. Jahrhunderts, in einem Bande multa opera Galieni ${ }^{24}$. Giovanni TorTELLI, der Bibliothekar Papst Nikolaus' V., schreibt in seiner Medizingeschichte ${ }^{25}$, daß sich das Gesamtwerk Galens nach der Aussage eines griechischen Arztes auf 150 Traktate belaufe. Im Jahre 1475 befanden sich in der Vaticana laut einem Bibliotheksverzeichnis ${ }^{26}$ : «Galieni et Aetii ali-

${ }^{20}$ R. SAbBadini, Le scoperte dei codici latini e greci ne' secoli XIV e XV, Firenze 1905 (= 2. Bd. der «Biblioteca storica del rinascimento»), S.43 ff. (mit Sekundärliteratur); R. Sabbadini, La scuola e gli studi di Guarino Guarini Veronese, Catania 1896, S. 10-6; E. Legrand, Cent-dix lettres grecques de François Filelfe, Paris 1892.

${ }^{21} \mathrm{Zu}$ Nikolaus V. s. L. Pastor, Geschichte der Päpste seit dem Ausgang des Mittelalters, 1. Bd. 2. Auflage, Freiburg i.Br. 1891, S. 293 ff., zu den griechisch-lateinischen Übersetzern unter Nikolaus V. siehe S. 443 ff.; vgl. auch Voigt 1893, S. 180 ff.; Sandys 1908, S. 65.

22 Theodor Gaza übersetzte die Aphorismen des Hippokrates, vgl. Legrand III, S. 157-8. Francesco Filelfo übersetzte die dem Galenos zugeschriebene Schrift Introductorium ad medicinam (KLEBS, in Osiris IV, 141).

${ }^{23} \mathrm{Vgl}$. das grundlegende Werk von F. MilkaU, Handbuch der Bibliothekswissenschaft, 2. Auflage, III. Bd., 1955, S. 505-59 (Renaissance-Bibliotheken), für die Marciana und Laurenziana in Florenz S. 514 ff., für die Vaticana S. 519 ff., für die Marciana in Venedig S. 527 ff.; vgl. dazu auch M. Luxoro, La biblioteca di San Marco nella sua storia, Firenze 1954.

${ }^{24}$ E. MüNtZ et P. FABre, La bibliothèque du Vatican au XVe siècle, Paris 1887 (= Müntz und Fabre), S. 340.

${ }^{25}$ Giovanni Tortelli, Della medicina e dei medici, Ed. L. Belloni und D.M. Schullian, Milano 1954, S. 15: «Nam ut a medico quodam greco viro egregio didici, centum et quinquaginta varia opera in medicine facultate composuit.»

${ }^{26}$ Müntz und Fabre, S. 234-5. 
qua ... Hippocratis opera ... Hippocratis omnia ... Galieni expositio in pronosticis Hippocratis ...»

Kardinal Bessarion ${ }^{27}$, der illustre byzantinische Theologe und Humanist, der am Unionskonzil eine entscheidende Rolle spielte, zum römischkatholischen Glauben übertrat und beinahe Papst geworden wäre, vermachte im Jahre 1468 der Stadt Venedig einen reichen Schatz an lateinischen und griechischen Handschriften ${ }^{28}$. Seine griechische Handschriftensammlung war die damals größte Kollektion griechischer Kodizes überhaupt. Galen, Aetios und Paulus von Ägina waren in dieser Schenkung in beachtlicher Weise vertreten ${ }^{29}$. Bessarion hatte schon vor dem Untergang des byzantinischen Reiches, in steigendem Maße aber nach dem Falle Konstantinopels, an griechischen Handschriften sammeln lassen, was immer zu bekommen war. Er hatte dabei den klaren Plan vor Augen, die Kontinuität der griechischen Tradition zu sichern. In seinem Widmungsschreiben an den Dogen und den Senat von Venedig führte Bessarion aus: «... Quamvis autem huic rei toto animo semper incubuerim, ardentiori tamen studio post Graeciae excidium et deflendam Byzantii captivitatem in perquirendis graecis libris omnes meas vires, omnem curam, omnemque operam, facultatem industriamque consumpsi. Verebar enim et vehementissime formidabam, ne cum ceteris rebus tot excellentissimi libri tot summorum virorum sudores atque vigiliae, tot lumina orbis terrae brevi tempore periclitarentur atque perirent ... sicque cuncta fere sapientium graecorum opera, praesertim quae rara et inventu difficilia, coegimus $\ldots{ }^{30}$.

Für Bessarion waren griechische Abschreiber tätig, die seine Manuskripte vervielfältigten. So schrieb Johannes Rhosos aus Kreta ${ }^{31}$ unter anderen Galen-Handschriften für ihn ab, und der gleiche Kopist arbeitete auch für Lorenzo de' Medici in Florenz.

${ }^{27}$ L. Mohler, Kardinal Bessarion als Theologe, Humanist und Staatsmann, 1. Bd. (= Darstellung), 3. Bd. (= Aus Bessarions Gelehrtenkreis), in Quellen Forsch. Geb. Gesch., Vol. $X X$, 1923, Vol. XXIV, 1942 (= Mohler 1923 und 1942).

${ }^{28}$ Verzeichnis der Handschriftenschenkung Bessarions an die Stadt Venedig s. bei H. Омоnт, Revue des bibliothèques IV, 1894, 129-87 (= Omont 1894). E. G. VogeL, Bessarions Stiftung oder die Anfänge der S. Marcusbibliothek, in Serapeum 2. 1841 90-107.

${ }^{29}$ Omont 1894, S. 157, Nr. 206-11.

${ }^{30}$ Mohler 1942, S. 541-3 (= Widmungsschreiben an Dogen und Senat von Venedig); dasselbe auch abgedruckt bei Omont 1894, S. 138-40.

${ }^{31}$ M.Vogel und V. Gardthausen, Die griechischen Schreiber des Mittelalters und der Renaissance (XXXIII. Beih. Zbl. Bibliothekswesen), Leipzig 1909, S. 187-90; vgl. auch J. Mewaldt, Corpus Medicorum Graecorum V, 9, 1 (1914) praefatio, S. XV. 
Von großer Wichtigkeit für die griechische Galen-Tradition wurde auch jene berühmte Handschriften-Expedition, die Janos LaSKaris für Lorenzo den Prächtigen in den Jahren 1491/92 in den Orient unternahm, von wo er rund 200 griechische Handschriften zurückbrachte ${ }^{32}$. In einem Verzeichnis der von Laskaris eingesehenen oder gekauften Handschriften befinden sich eine große Zahl galenischer Werke ${ }^{33}$.

Auch in Privatbibliotheken wurden Galen-Handschriften angelegt. NIGcolò Leoniceno (1426-1524), einer der ersten bedeutenden Übersetzer in der Reihe der Philologen-Mediziner, spielte als Vermittler von Aristotelesund Galen-Handschriften eine bedeutende Rolle ${ }^{34}$.

Die Aristotelesaldina ging teilweise auf Handschriften aus seinem Besitze zurück ${ }^{35}$, und die griechische Ausgabe der galenischen Therapeutika, das erste und einzige größere galenische Werk in griechischem Text vor der Editio aldina, fußte ebenfalls auf Kodizes, die Leoniceno dem Herausgeber Niкolaus Blastos zum Selbstkostenpreis überlassen hatte ${ }^{36}$.

$32 \mathrm{Zu}$ Janos Laskaris vgl. Legrand I, S. CXXXI-CLXII; E. G. VogeL, Janus Lascaris, in Serapeum 10 (1849) 65-74. Für die Handschriftenexpedition vgl. E. G. VogeL, Litterarische Ausbeute von Janus Laskaris Reisen im Peloponnes um's Jahr 1490, in Serapeum XV , 1854, 154-60 (Galen-Handschriften S. 158-9); K. K. MüLLER, Neue Mittheilungen über Janos Laskaris und die Mediceische Bibliothek, in Zbl. Bibliothekswesen 1 (1884) 333-412 (Galen-Handschriften S. 376, 380-1, 390-1, 396, 399-400, 402, 405-7); Legrand I, S. CXXXII ff. (= LAskaris Handschriften-Reise in den Orient); Legrand II (1885) S. 325-7 (= Kaufvertrag des LAsKaris für diese Handschriften). Vgl. dazu noch ein von LASKARIS aufgenommenes Inventar der Mediceeischen Bibliothek im Jahre 1495 bei E. Piccolomini, Inventario della libreria medicea privata compilato nel 1495, in Archivio stor. ital., Ser. 3, T. XX (1874) 51-94 (Galen-Handschriften S. 93).

33 Vgl. Anm. 32 (K.K. Müller).

34 J.L. HeIberg, Beiträge zur Geschichte Georg Valla's, XVI. Beih. Zbl. Bibliothekswesen 1896, S. 71 (= Brief des Leonicenus an VAlla vom 19. Juli 1491), S. 72 (= Antwort VALLAS), die Korrespondenz berührte unter anderem auch den Wortlaut gewisser Stellen in Galen-Handschriften.

35 Botfield 1861, S. 199 (Widmungsbrief des Aldus an Alberto Pio da Carpi zum Aristoteles graecus.

${ }^{36}$ Legrand I, S. 75, und Legrand II, S. 312-3 (= Briefe des Marcus Musurus über seine bei Leonicenus unternommenen Schritte zum Erwerb der galenischen TherapeutikaHandschriften für Nikolaus Blastos. Bibliographische Beschreibung und Faksimileabbildungen aus diesem Erstdruck der griechischen Therapeutica vgl. Legrand I, S. 74-5, und Poynter 1954, S. 52 (Nr. 245) und 6. Abbildung. Es ist bemerkenswert, daß gerade zwei Griechen, Nikolaus Blastos und Zacharias Kallierges, beide aus Kreta stammend, zum ersten Male ein größeres Galen-Werk in griechischem Drucke herausbrachten. Sie fügen sich damit würdig in die Bemühungen um den Galenus graecus ein, die ein Bessarion und Janos LASKaris neben zahlreichen anderen Byzantinern leisteten. 
Giongio ValLA ${ }^{37}$, Arzt und Humanist, Schüler des Konstantin LaskaRIS $^{37 a}$, besaß Galen-Handschriften, die später in die Bibliotheca Estense nach Modena übergingen. Valla gehört ebenfalls zu den Pionieren unter den humanistischen Galen-Übersetzern. Seine Übertragungen erschienen in Galen-Inkunabeln ${ }^{38}$ und in Frühdrucken ${ }^{38 a}$.

Als Aldus Manutius gegen Ende des 15. Jahrhunderts mit der systematischen Ausgabe der griechischen Klassiker in ihrer Ursprache begann, lag das handschriftliche Material für die Edition Galens bereit.

Im Laufe der riesigen Editions- und Druckerarbeit, die Aldus vollbrachte, kam er immer wieder auf sein Anliegen zu sprechen, neben der poetischen, philosophischen und wissenschaftlichen Literatur auch die antiken Ärzte herauszugeben. Zum ersten AristotelesBand (1495) schrieb Aldus ${ }^{39}$ : «... sed succurrendum est studiosis bonarum literarum ... imprimentur etiam grammatici, oratores, historici et quicumque profuturi videbuntur studiosis.» Im zweiten Aristoteles-Band bemerkte Aldus ${ }^{40}$ : «... Dabimus etiam et Hippocratis et Galeni omnia et caeterorum illustrium qui in medicina scripserunt. » In der Vorrede zur Editio princeps des Aristophanes (1498) unterstreicht Aldus die Bedeutung der griechischen Ärzte ${ }^{41}$ : "Hippocrates, Galenus, Paulus et alii in medicina aexcellentissimi viri omnia quae ad artis spectant cognitionem copiosissime verissimeque literis commendarunt ... Errant meo iudicio multum qui se bonos philosophos medicosque evasuros hoc tempore existiment, si expertes fuerint literarum graecarum ...» Im Jahre 1514 wies Aldus darauf hin, daß der Arzt und Humanist Victor Bergomas die Schriften des Galen gründlich bearbeitet und kommentiert habe. Seine Manuskripte seien jedoch zusammen mit seiner Bibliothek einer Feuerbrunst zum Opfer gefallen ${ }^{42}$.

Auch Wilhelm Cop - ein aus Basel stammender Arzt, der in Paris wirkte und die dortige «Galen-Renaissance» mit vielbeachteten Übersetzungen galenischer Schriften im humanistischen Sinne inaugurierte - bemerkte in der Vorrede zu seiner Übersetzung der Praecepta salubria des Paulus von Ägrna, es sei nun Zeit, die Texte der griechischen Ärzte in der Originalsprache und ursprünglichen Reinheit wiederherzustellen: «Ergo quum magna iam antiquorum optimorumque voluminum, tum oratorum et poetarum, tum philosophorum, copia Aldi Manutii viri undecunque doctissimi industria nobis restituta sit, laborandum esse duxi, ut Medicinae quoque auctores ad pristinae dignitatis lucem resurgant. ${ }^{42}$ a

${ }^{37}$ Vgl. Heiberg 1896.

37a Vgl. Anm. 19 (H. RABE).

${ }^{38}$ Vgl. Anm. 15.

38 a Vgl. A. A. Renouard, Annales de l'imprimerie des Estienne, $2^{\mathrm{e}}$ éd. Paris 1843, S. 20.

${ }^{39}$ Botfield 1861, S. 195-6.

${ }_{40}$ Botfield 1861, S. 200; Renouard 1834, S. 11.

41 Botfield 1861, S. 218.

42 Legrand I, S. 99-100.

42a Pauli Aeginetae precepta salubria Guilielmo Copo Basileiensi interprete, Argentorati ex aedibus Mathiae Schurerii MDXI, praefatio; Die Vorrede ist auch bei Renouard 1843, 
Nach dem Tode des Aldus, als die Weiterführung der aldinischen Offizin gefährdet erschien, beschwor Marcus Musurus alle Freunde der guten Wissenschaften, sie sollten Asulanus in seinem Vorhaben, das Werk des Aldus fortzusetzen, kräftig unterstützen ${ }^{43}$. Dann wären noch Galen, Pausanias und andere Autoren zu erwarten ${ }^{44}$.

Im Jahre 1525 erschien endlich der griechische Galen in aedibus Aldi et Andreae Asulani soceri, Venetiis, als mächtiges, fünfbändiges Foliowerk ${ }^{45}$. Eine Gemeinschaft von Ärzten, Humanisten und Druckern wirkte bei der Edition des Galenus graecus zusammen, wie es im Hause des Aldus seit jeher üblich gewesen, wo ein Thomas Linacre ${ }^{46}$ und ein Erasmus ${ }^{47}$ als Textrezensenten und Herausgeber gearbeitet hatten, und wo in der «Neuen Akademie» des Aldus die verschiedenen Fachwissenschaften durch besondere Gilden $\Phi v \lambda \alpha i$ mit ihren speziellen Vertretern in Erscheinung traten ${ }^{48}$.

Bei der Editio aldina des Galen wirkten mit: Die Familie der Torresani aus Asola ${ }^{49}$ mit dem Vater Andreas und den Söhnen Federicus und Franciscus. Der letztere, Giovanni Francesco D'Asola, war ein bekannter Gräzist. Er übersetzte u.a. Plutarch und Lukian, und zahlreiche Pariser Handschriften sind mit seinen ex libris versehen ${ }^{50}$. Die ärztlichen und humanistischen Mitarbeiter waren: Als oberster Textgestalter der Arzt und Humanist Giovanni Battista Oppizzoni aus Pavia ${ }^{51}$. Ihm standen

S. $8 \mathrm{ff}$., abgedruckt (= Ausgabe der Praecepta salubria in der Übersetzung Cops bei H. Estienne I, Paris 1510).

${ }^{43}$ Legrand I, S. 133.

${ }^{44}$ Ibid.

${ }^{45}$ Bibliographische Beschreibung siehe bei Renouard 1834, S. 101-2; S.F.W. HofFmanN, Bibliographisches Lexicon der gesammten Litteratur der Griechen, 2. Theil, 2. Auflage, Leipzig 1839, S. 122.

${ }^{46}$ W. OsLer, Thomas Linacre, Cambridge 1908 (Linacre Lecture 1908), S. 12-3; Botfield 1861, S. 199, 239 (= Vorrede des Aldus zu Proclus, De sphaera: «... Procli sphaeram ... eam Thomas Linacrus Brittanus docte et eleganter latinam nuper fecit ...»). - GALEN, Editio aldina, Venedig 1525, Vol. V, Vorrede von ANDr. Asulanus an Opizo, fol. Iv «... et Thomas Linacrus Aldi nostri contubernio ad aliquot annos usus ...»-Vgl. auch J.F. Fulton, Early Medical Humanists: Leonicenus, Linacre and Thomas Elyot, in New England J. Med. 205 (1931) 141-6, 158-9, Anm. 18.

47 J. Huizinga, Erasmus (deutsch von W. KäGI) Basel 1936, S. 78-9.

${ }^{48}$ Firmin-Didot 1875, S. 151.

${ }^{49}$ Vgl. Anm. 2.

${ }^{50}$ Vogel/Gardthausen, Die griechischen Schreiber ..., op. cit., S. 446; H. Омоnт, Catalogues des manuscrits grecs de Fontainebleau sous François $1^{\text {er }}$ et Henri II, Paris 1889, S. IV, XXIV.

51 Vgl. Anm. 3. 
junge Humanisten und Humanistenärzte zur Seite, die aus den nordischen Humanistenzirkeln nach Italien gereist waren, um ihre Ausbildung in den Humaniora und der Heilkunde zu verbessern und die bei dieser Gelegenheit von Asulanus und Oppizzoni in die Editionsarbeit eingespannt wurden.

John Clement ${ }^{52}$, ein junger Engländer, stammte aus dem Humanistenzirkel um Thomas More, W. Grocyn und John Colet ${ }^{53}$. Er hatte eine Zeitlang im Moreschen Haushalt das Amt eines Hauslehrers innegehabt ${ }^{54}$, war mit Thomas Linacre bekanntgeworden und kam Anfang der zwanziger Jahre nach Norditalien. Im März 1525 wurde er in Siena zum Doktor der Medizin promoviert. Gleich darauf kam er zu Asulanus und Oppizzoni nach Venedig, um für die Editio aldina die Kommentare Galens zu den Epidemien I und III des Hippokrates zu bearbeiten. Clement erwarb sich in Italien Galen-Handschriften, die er nach England mitnahm und die später in die Pariser Bibliothek gelangten ${ }^{55}$. Ein Teil dieser Handschriften haben der Aldina als Druckvorlagen gedient ${ }^{56}$.

Ein weiterer Mitarbeiter im Stabe des Oppizzoni war der Theologe und Humanist Thомas Lupsetus (Lupset, Lupshed) ${ }^{57}$. Er war Landsmann von John Clement und gehörte ebenfalls zum Kreise der englischen Humanisten um John Colet, More, Linacre und Erasmus. Galen war ihm kein unbekannter Schriftsteller, da er Linacre bei der Edition lateinischer Galen-Übersetzungen geholfen hatte. Auch Lupsetus kam anfangs der zwanziger Jahre nach Italien ${ }^{58}$.

Aus dem Leipziger Gräzistenkreis kam um dieselbe Zeit Georg Agricola ${ }^{58 a}$, der später berühmt gewordene Arzt und Mineraloge, ein Schüler des Petrus Mosellanus,

52 E. Wenkebach, John Clement, ein englischer Humanist und Arzt des 16. Jahrhunderts, in Stud. Gesch. Med., Heft 14, 1925 (= Wenkebach 1925); E. Wenkebach, Beiträge zur Textgeschichte der Epidemienkommentare Galens, in Abh. Preuß. Akad. Wiss., philos.-hist. Kl. 1927, Nr. 4. (= Wenkebach 1927), S. 36 ff.

${ }^{53}$ Ibid., vgl. auch F. SеЕвонм, The Oxford Reformers John Colet, Erasmus and Thomas More, 2. Auflage, London 1869.

${ }^{54}$ Wenkebach 1925, S. 4 ff.

${ }_{55}$ Wenkebach 1925, S. 15; Wenkebach 1927, S. 25, 37.

${ }^{56}$ Wenkebach 1927, S. 25. Es handelt sich um die Pariser griechischen Handschriften 2165 und 2167. Wenkebach 1925, S. 15, S. 54, Anm. 51.

${ }^{57}$ Vgl. Dictionary National Biography XXXIV (1893), S. 285; Wenkebach 1925, S. 45 ff.

${ }^{58}$ Тн. Lupsetus überwachte als Korrektor die Ausgabe von LiNAcres Übersetzung der galenischen Schrift De sanitate tuenda. Vgl. Wenkebach 1925, S. 45 Anm. 26; vgl. auch den Brief von Guillaume BudÉ an Lupsetus, der am Beginn der bei Maheu in Paris gedruckten Galen-Schrift Methodus Medendi steht (Galeni Methodus medendi vel de morbis curandis, Thома Linacro Anglo interprete, Lutetiae MDXIX, ap. Desiderium Maheu). Am Beginn dieser Ausgabe, fol. 2r steht: Gulielmus Budaeus Thomae Lupseto Anglo S.D. Quos mihi libros therapeuticos credideras, Lupsete doctissime, eos ad te remitto ....

58a E. Darmstaedter, Georg Agricola, Leben und Werk, München 1926 (Münch. Beitr. Gesch. Lit. Natwiss. Med. Heft I), S. 82; H. Hartmann, Georg Agricola, Stuttgart 1953 («Große Naturforscher» Bd. XIII) S. 16-7. 
nach Venedig. Auch er wird von Asulanus zusammen mit den eben erwähnten englischen Humanisten als Mitarbeiter und Helfer des Oppizzoni bezeichnet ${ }^{59}$.

Als Druckvorlagen für die Galenaldina dienten im allgemeinen eine oder auch mehrere Handschriften. Diese stammten meist aus dem 15. Jahrhundert, teilweise handelte es sich auch um junge Abschriften aus dem 16. Jahrhundert. Die Güte der Handschriften, mehr oder weniger dem Zufall des Fundes anheimgestellt, war verschieden.

Ein eindrückliches Zeugnis für eine Druckvorlage der Aldina stellt der Codex Reginensis gr. Vatican. 173 dar. Aus dieser im 15. Jahrhundert geschriebenen Handschrift ist der galenische Kommentar zur hippokratischen Schrift De natura hominis in die Aldina abgedruckt worden. Einen Teil der zierlichen Schrift dieses Codex sieht man stellenweise durchgestrichen, und an den Rand der Handschrift ist von anderer Hand ein veränderter Text hingeschrieben, der aus einer anderer Handschrift entnommen wurde ${ }^{60}$. Der so veränderte Text, aber auch die angedeutete Paginierung, die beide mit der Galenaldina übereinstimmen, erweisen diese korrigierte Handschrift als Druckvorlage der Aldina. In ähnlicher Weise lassen sich auch aus dem Codex Parisinus gr. 2165 zahlreiche Galen-Handschriften als Quellen für den Druck der Galenaldina identifizieren ${ }^{61}$. Eine andere Handschrift, aus dem Besitze des Leonicenus stammend, diente als Vorlage für den Aldinentext der galenischen Schrift De usu partium ${ }^{62}$.

${ }^{59} \Gamma \alpha \lambda \eta v o \tilde{v}$ E' Galeni librorum pars quinta, Venetiis 1525 (fol. IIr) ...» Sed quando tu (= Opizo) unus velut Imperator bellum hoc patrare tam difficile et arduum non poteras, et grati est animi fateri cui debeas: agent etiam gratias graeci, latinique restituti Galeni Clementi, et Odoardo, et Roseo Britannis, qui te veluti Centuriones acerrimi in victoria hac consequenda plurium adiuvere: sed nec Lupsetum in hoc munere contempseris, qui omnibus elaboravit nervis, ut quatenus fieri posset, laboranti tibi veluti Atlanti, dum Axem humero torques, tanquam alter Hercules successerit: sed nec Georgius Agricola non parvam laudem est meritus, nam et ipse in emendando Galeno nihil sibi ad industriam et laborem reliqui fecit ...» Außer Clement und Lupshed arbeiteten noch zwei weitere englische «Linacrianer», Anthony Rose (Roseus) und Edward Wotton (Odoardus) an der Galenaldina mit, vgl. Wenkebach 1925, S. 11, 14, 51 (Anm. 43), 57. ${ }^{60}$ Vgl. Mewaldt 1912. Hier auch eine Faksimileseite dieses Cod. Reginensis Vat. 173. '

${ }^{61}$ Vgl. Anm. 56; Mewaldt 1912, S. 902-3.

${ }^{62}$ Galeni de usu partium, Ed. G. Helmreich, Vol. I (Teubner), Leipzig 1907, praefatio, S. IX, X (es handelt sich hier um den Cod. Par. gr. 2148, saec. XV.). Als weitere Belege zur handschriftlichen Grundlage der Galenaldina vgl. noch: Ackermann (Kuehn I, S. XVII ff.); G. HeLmreich, Galeni de elementis ex Hippocratis sententia, Erlangen 1878, praefatio, S. XII; idem: Galeni de optima corporis constitutione, in Progr. Kgl.-hum. Gymn. in Hof 1900/1901, praefatio, S. 5; Galeni scripta minora, Vol. II, Leipzig 1891, praefatio, S. LVI; J. Mewaldt, Corpus Medicorum Graecorum V, 9, 1, praefatio, S. XI, XII, XVII ff.; I. Müller, Galeni libellus quo demonstratur optimum medicum

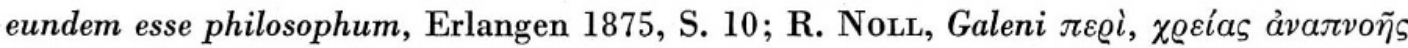
libellus, Diss. Marburg 1915, praefatio, S. XXIII ff.; H. SснӧNe, Verbesserungen zum Galentext, in Sber. Preuß. Akad. Wiss., philos.-hist. Kl. 1924, S. 94-106; H. WAGNER, 
Der humanistische Grundzug der Galenaldina, und das humanistische Milieu, in dem sie entstand, spiegelt sich deutlich in den Vorreden zu den einzelnen Bänden ${ }^{62 a}$.

Im Geleitwort zum fünften Bande stellt Andreas Asulanus fest, daß die griechischen Ärzte bisher nur in barbarischer Übersetzung bekannt gewesen seien ${ }^{63}$. Mit echt humanistischem Selbstgefühl ruft er aus, daß erst jetzt, im griechischen Gewande, Galen wiederauferstanden sei, um den barbarischen arabischen Galen zu ersetzen, der durch die linguistischen Unkenntnisse früherer Übersetzer nur in entstellter Gestalt bekannt gewesen sei ${ }^{64}$. Während Asulanus die mittelalterlichen arabisch-lateinischen Übersetzer hart beurteilt, läßt er den Arabern selbst insofern Gerechtigkeit widerfahren, als er ihren Eifer um die Übernahme der griechischen Medizin, zu einer Zeit, als diese in Europa und sogar in Italien in Vergessenheit geriet, zugibt ${ }^{65}$. Höchstes Lob spendet er den neueren humanistischen Übersetzern, so Nicolaus Leonicenus ${ }^{66}$ in Italien, Wilhelm Cop $^{67}$ in Frankreich und

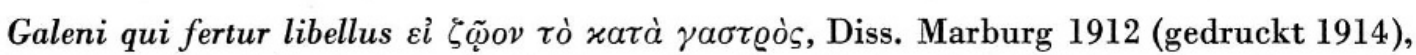
S. VI ff.; Wenkebach 1927, S. 6, 25, 37 ff. - Für die handschriftlichen Grundlagen der galenischen Schrift De sanitate tuenda vgl. K. КосH, Corpus Medicorum Graecorum V, 4, 2, praefatio, S. VII, XXII; für die Schrift De alimentorum facultatibus vgl. G. HeLmREICH, Corpus Medicorum Graecorum, V, 4, 2, praefatio, S. XXXIX.

62a Vgl. dazu allgemein K. Schotтenloher, Die Widmungsvorrede im Buche des 16. Jahrhunderts, in Reformationsgeschichtliche Studien und Texte, Heft 76/77, Münster (Westfalen) 1953; Die Praefationes der einzelnen Aldinenbände sind auch abgedruckt bei Botfield 1861, S. 352-65.

${ }^{63}$ Galenus, Ed. aldina, 1525, Vol. V, praefatio (fol. Ir): «... Quod et si Galeni quaedam et Hippocratis in nostram linguam versa legerentur opera nonulla: ea tamen istiusmodi erant, ut praestaret in Avicennae et istiusmodi farinae scriptorum monimentis operam insumere quam in hisce (nämlich den griechischen Autoren) tam infeliciter tamque faede ac barbare conversis, bonum ocium collocare.»

${ }^{64}$ GALENUS, Ed. aldina, Vol. V, praefatio (fol. IIr): «... omnisque illa barbaries Italiae finibus expellatur ... tum vero Galenum pene integrum ab inferis excitavimus ...»

${ }^{65}$ Galenus, Ed. aldina, Vol. V, praefatio (fol. Iv): «... sic optimae quaeque artes apud nostros a stirpe interciderant, ut nihil iam nisi Gotthicum et Sarracenicum altrix haec gentium, et Deorum pene dixerim parens Italia (pro nefas) redderet illaeque ipsae artes cum Imperii amplitudine gravi sane iactura ad Arabes transferrentur ... » $\mathrm{Zu}$ den kulturund medizinhistorischen Betrachtungen und Auffassungen der Humanisten-Ärzte vgl. L. Edelstein, Andreas Vesalius the Humanist, in Bull. Hist. Med. XIV (1943) 547-61.

${ }^{66} \mathrm{Zu}$ Leonicenus vgl. L. Thorndike, History of Magic and Experimental Science, Vol. IV, 1934, S. 593-610 (mit Sekundärliteratur); P. CAPPARonI, Un ritratto di Niccolò Leoniceno, in Riv. stor. sc. med. nat. An. XXXIII, vol. XXIV (1942) 1-14; J. F. Fulton, Eearly Medical Humanists l.c., 1931; J.F. Fulton, The Great Medical Bibliographers, Philadelphia 1951, S. 8-9.

${ }^{67} \mathrm{Zu} \mathrm{W}$. Cop vgl. in erster Linie E. Wickersheimer, in Bull. Soc. franç. hist. méd. XII (1913), 336-42 (hier auch Bibliographie der Galen-Übersetzungen Cops), und in Dictionnaire biographique des médecins en France au moyen âge, Paris 1936, S. 235-39. Für den 
Thomas Linacre ${ }^{68}$ in England. Diese Ärzte hätten erst die Autorität der Araber gebrochen $^{69}$, sie erst hätten Galen richtig lateinisch reden gelehrt ${ }^{70}$. Das formalästhetische Empfinden der Humanisten und ihre Ablehnung der latino-barbari kommt hier so recht zum Ausdruck.

Das Gesamtwerk des Galenus widmet Andreas Asulanus Papst KLEMENS VII., dem Mediceer und Neffen von Lorenzo magnifico ${ }^{71}$. Er wird als Beschützer der bonae literae und als Mäzen der Humanisten gewürdigt ${ }^{72}$. Der zweite Band, dessen Widmung Federicus Asulanus verfaßte, ist ALBerto Pio von Carpi zugedacht. Alberto Pio, Neffe des berühmten Pico della Mirandola, war ehemals Zögling des Aldus gewesen und hatte sich seit jeher als treuer Freund und Förderer der aldinischen Druckerei erwiesen ${ }^{73}$. Den dritten Band widmet Franciscus Asulanus dem Bischof Johannes Matthaeus Gibertus aus Verona, dessen Mäzenatentum Franciscus gebührend feiert ${ }^{74}$. Im vierten Bande, dessen Geleitwort wiederum

Humanistenkreis um Cop in Paris vgl. L. Delaruelle, Etudes sur l'humanisme français, Guillaume Budé, Paris 1907, S. 91; J. Paquier, L'université de Paris et l'humanisme au début du XVI $I^{e}$ siècle. Jérôme Aléandre, Paris 1899 (= Paquier 1899), S. 54/55.

${ }^{68}$ W. OsLer, Thomas Linacre, Cambridge 1908.

${ }^{69}$ Galenus, Ed. aldina, Vol. V, praefatio (fol. IIr): «... Caeterum italica re non multo post revivescente fregerunt authoritatem arabicae huiusce linguae primi illi, quos retuli, viri doctissimi ..."

${ }^{70}$ Galenus, Ed. aldina, Vol. V, praefatio (fol. Ir bis Iv): «... Primus igitur e nostris nostra memoria Leonicenus auspicato et Galenum latine loqui docuit ... nam et Copus Gallorum Regis medicus Aeginetae librum, et Galeni de locis affectis adeo eleganter et pure vertit, ut tu medio illum Latio natum, cum eius scripta legis, adiurare possis: et Thomas Linacrus Aldi nostri contubernio ad aliquot annos usus, ipsam Galeni methodum, seu de morbis curandis libros ave tam felici latinitate donavit ...» Eine ähnlich hohe Bewertung der neueren zeitgenössischen humanistischen Mediziner hatte auch Erasmus in einem Brief an Capito aus den Jahren 1516/17 gegeben (Allen, Opus Epistolar. Erasmi Roterodami II, S. 489, Nr. 541): «... ut certa pene spes sit disciplinas omneis multo purgatiores ac synceriores in lucem prodituras? ... Medicinam vero quam multi vindicant! Romae Nicolaus Leonicenus, apud Gallos Gulielmus Copus ac Joannes Ruellus, et apud Britannos Thomas Linacrus.»

${ }^{71} \mathrm{Zu}$ Papst Klemens VII. vgl. Enciclopedia cattolica III (1949), Spalte 1821-7 (mit Bibliographie); L. Pastor, Geschichte der Päpste IV, 2, 1.-4. Auflage, Freiburg i.Br. 1907, S. $161 \mathrm{ff}$.

${ }^{72}$ Galenus, Ed. aldina, Vol. I, praefatio, fol. Iv: «... Praeterea quis est, qui nesciat non hoc solum, sed quicquid etiam in literis elegans, atque perfectum iampridem parit Italia, Medicae imprimis familiae deberi?»

${ }^{73}$ Firmin-Didot 1875, S. 8.

${ }^{74}$ Galenus, Ed. aldina III, praefatio, Joanni Matthaeo Giberto Episcopo Veronensi Clementis VII. Pont. Max. Datario Franciscus Asulanus S.; Zu Gian Matreo Giberti, 
Andreas Asulanus schrieb, wird der Humanist und Theologe Hieronymus Aleander ${ }^{75} \mathrm{dem}$ Leser vorgestellt. Andreas preist in höchsten Tönen Aleanders Verdienste um die Einführung des Griechischen in Frankreich ${ }^{76}$ und hebt seine engen Beziehungen zum Heiligen Stuhl hervor. Den fünften Band widmet der Druckherr Andreas Asulanus dem Hauptherausgeber Giovanni Battista Oppizzoni (Joannes Baptista Opizo). Er stellt ihn als Arzt und Humanisten aus Pavia vor, der beim Zustandekommen dieses Werkes die treibende Kraft gewesen sei, und dem Galenos seine alte Würde und Reinheit verdanke ${ }^{77}$. Hierauf dankt Asulanus all den jungen Humanisten, die aus den nordischen Ländern in die hellenische Zentrale nach Venedig kamen, um Oppizzoni in seinem Riesenunternehmen beizustehen ${ }^{78}$.

Für den Medizinhistoriker besonders bedeutungsvoll ist die sachliche Gliederung des Corpus Galenicum in der Galenaldina. Hier verrät sich die ärztliche Hand des Oppizzoni. Im ersten Bande sind die kurzen, in die Medizin einführenden Schriften (F. 1-24) enthalten, dann die Physiologika und Anatomika. Unter den anatomisch-physiologischen Werken finden sich solche, die bisher dem westlichen Kulturkreis nur dem Titel nach bekannt waren ${ }^{79}$, wie etwa die wichtige Schrift De anatomicis administrationibus (F. 45-88), oder De placitis Hippocratis et Platonis (F. 119 ${ }_{-}$

Datar und Ratgeber Klemens' VII., vgl. L. PAston, Geschichte der Päpste IV. Band, Freiburg i.Br. 1907, S. 609-20.

${ }^{75} \mathrm{Zu}$ Aleander siehe Enciclopedia cattolica I (1948), Spalte 741-2.

${ }^{76}$ Paquier 1899.

${ }^{77}$ Ed. aldina, Vol. I, praefatio (fol. Ir) Andreas Asulanus führt dort aus: «... Joannis Baptistae Opizonis Papiensis hominis cum probi, atque industrii, tum in literis plurimum, et in medendi arte ut quam maxime versati: qui ut verum fatear, me ad suscipiendum hoc munus apprime hortatus est: et ad perficiendum quam maxime iuvit »; GALENUS, Ed. aldina, Vol. V, praefatio, Andreas Asulanus Joanni Baptistae Opizoni patritio papiensi, medicoque praestantissimo S. ... (fol. IIr): «... Perpulisti igitur tu (nämlich Opizo) ... ut Galenum primum adgrederer ... Quare nulli neque labori neque impensis parcentes, vel tuo unius exemplo, quem pudebat non sequi in opere tam honesto et utili: damus tandem Galeni multo maximam partem scriptorum... atque hunc quintum tomon tibi dicamus uni meritissimo: siquidem tuus est Galenus: et libra et aere quod aiunt, et mancupio: tibi enim ille libertatem debet uni: tibi vitam, tibi dignitatem restitutam.»

${ }^{78}$ Vgl. Anm. 59. Zur mühevollen Arbeit, für die Editio aldina die nötigen griechischen Handschriften aufzutreiben, bemerkt Andreas Asulanus (Ed. aldina, Vol. I, fol. Ir): «... quotquot usquam fere tota Graecia, simulatque Italia reperiri codices potuerunt: incredibili cura, sumptuque supra quod dici absque ulla mendacii aut vanitatis suspicione possit: conquisivi ...»

${ }^{79}$ Vgl. dazu Ch. Singer und C. Rabin, A Prelude to Modern Science (Tabulae sex of Vesalius) Cambridge 1946, S. XV ff. und XXV ff. 
$\left.167^{v}\right)$. Die wichtigste anatomische Schrift Galens, De anatomicis administr., hatte zwar der aus Athen stammende Demetrios Chalkondyles ins Lateinische übersetzt ${ }^{80}$, aber im Druck war dieses Werk erst im Jahre 1529 auf Betreiben Berengar da CARPIS erschienen ${ }^{81}$, und eine große Verbreitung und Wirkung hatte es daher vorher nicht gehabt. Im zweiten Bande der Aldina finden sich die pharmazeutischen und pharmakologischen Werke und in den dritten Band sind die diagnostischen, prognostischen und internistischen Schriften aufgenommen ${ }^{82}$. Im vierten Bande stehen die therapeutischen und hygienischen Schriften ${ }^{83}$ und im fünften Bande sind die galenischen Kommentare zu hippokratischen Werken enthalten.

Bei der «Galen-Renaissance», die sich in der ersten Hälfte des 16. Jahrhunderts vollzog ${ }^{84}$, spielte die Aldina vor allem als Grundlage für die lateinischen Galen-Übersetzungen der Humanisten und Philologenärzte eine wichtige Rolle. Ernst Wenkebach, einer der besten Kenner der humanistisch-philologischen Bearbeitung Galens im 16. Jahrhundert, bemerkte

${ }^{80}$ Legrand III, S. 326-7.

${ }^{81}$ V. Putri, Berengario da Carpi, Bologna 1937 (Classici italiani della medicina III), S. 161.

${ }^{82}$ Galenus, Ed. aldina, Vol. III, die Pulsschriften, fol. 1-83 v, die Schrift De locis affectis (in neuer Paginierung), fol. 27r-64.v.

${ }^{83}$ Galenus, Ed. aldina, Vol. IV, die Aderlaßschriften, fol. 1-14v, die Schrift De methodo medendi, fol. 20r bis 101r, die Schrift De sanitate tuenda (neue Paginierung), fol. 1-36r.

${ }^{84}$ Vgl. Anm. 5; Zum Pariser Galenismus vgl. noch: M.F. Ashley Montage, Vesalius and the Galenists, in Essays on the Evolution of Scientific Thought and Medical Practice, written in honour of Charles Singer, Vol. I, London/New York/Toronto 1953, S. 374-85; G. Rath, Charles Estienne, Anatom im Schatten Vesals in Sudhoffs Arch. Gesch. Med. Natwiss. XXXIX (1955) 35-43 (exakte Bearbeitung eines Einzelproblems, die einen guten Einblick in die Galenisten-Anatomie im Pariser Kreis gewährt). Zur Bibliographie der im Laufe des 16. Jahrhunderts zu großer Breite anschwellenden Galen-Editionen vgl.: L. Choulant, Handbuch der Bücherkunde für die ältere Medizin, Leipzig 184.1, Galen S. 98 ff. Ein ausführliches, besonders auch für die Einzelausgaben GaLENs wichtiges bibliographisches Verzeichnis: S. F. W. Hoffmann, Bibliographisches Lexicon der gesammten Litteratur der Griechen, 2. Auflage, 2. Theil, Leipzig 1839, S. 122-53 (neben den lateinischen Übersetzungen auch die neusprachlichen Galen-Übertragungen des 16. Jahrhunderts). Eine sehr ausführliche, aber systematisch etwas unübersichtliche Bibliographie der lateinischen Galen-Werke des 16. Jahrhunderts gibt D. CAMPBELL im 2. Bande seiner Arabian Medicine and its Influence on the Middle Ages, London 1926. Für die bedeutende Anzahl von Galen-Werken, die in Lyon gedruckt wurden, vgl. die einzigartige, von J. BAUdRIER zusammengestellte Bibliographie Lyonnaise, 12 Bände, Lyon/Paris 1895-1921 (Registerband Genf/Lille 1950); dieses Werk verfolgt über das ganze 16. Jahrhundert den Buchdruck, die Buchhändler und Drucker von Lyon. 
dazu $^{85}$ : «... so darf man von vornherein vermuten, daß die lateinischen Übersetzer in der Regel auf der Editio princeps (gemeint ist die Galenaldina) fußen.»

Kurze Zeit nach dem Erscheinen der Galenaldina ist eine gesteigerte Übersetzertätigkeit am Corpus Galenicum eingetreten. Erasmus von Rotterdam übersetzte im Jahre 1526 die drei kurzen, am Anfang des ersten Aldinenbandes stehenden Galen-Schriften ins Lateinische $^{85}$ a . In der Vorrede zu seinen Übersetzungen bemerkte Ersamus: «Prodiit totus Galenus sua lingua nobis loquens, cuius primitias ad te mitto, inflammandis ad rei medice studium iuvenum animis versas ... ${ }^{85} \mathrm{~b}$. $)$ WINTHER voN ANDERNACH ${ }^{86}$ der rastlose GalenÜbersetzer aus dem Pariser Galenistenkreis, benutzte die Aldina als Grundlage für seine Übertragungen. In der Vorrede zur lateinischen Übersetzung der Schrift De anatomicis administr. führt er aus ${ }^{87}$ : «Nos itaque novem illos libros, qui in vulgato codice habentur, in latinam orationem converture sumus agressi ... Porro auxit laborem exemplar ab Asulani officina profectum ...» JoHAnnes VAssaeus übersetzte aus der Aldina den Kommentar Galens zum Prorrheticum des Hippokrates ${ }^{88}$ und Hermann Crüser, Arzt und Jurist ${ }^{89}$, übersetzte den galenischen Kommentar zur hippokratischen Schrift De natura hominis aus der Aldina ${ }^{90}$. Joachimus Martinius Gandavus schickte seiner Übersetzung der galenischen Schrift De alimentorum facultatibus folgende Worte voraus ${ }^{90}$ a : "Non te latet, candide lector, quam multis in locis Graecus Galeni codex, qui ex Asulani officina prodiit, mutilus sit ac depravatus. Unicus autem hic nobis fuit ...»

Neben der Aldina, dem Grundstock für zahlreiche Galen-Übersetzungen, wurden auch die schwerer zugänglichen Handschriften von den Übersetzern zu Hilfe genommen. So benutzte Јон. Bernardus Felicianus aus Pavia für die Übersetzung der Schrift kat'iet-

85 E. Wenkebach, Abh. Preuß. Akad. Wiss., philos.-hist. Kl. 1928, Nr. 9, S. 42.

85 a Galeni ... exhortatio ad bonas arteis ... de optimo docendi genere, et qualem oportet esse medicum. D. Erasmo Roterodamo interprete. Parisiis (Jod. BadIus) 1526.

85b Ibid., Epist. nuncup., fol. 1r. Erasmus widmete diese Galen-Übersetzungen dem Arzte Johannes Antoninus aus Krakau, der ihn im Jahre 1524 behandelt hatte (vgl. R. NEwALD, Erasmus Roterodamus, Freiburg i.Br. 1947, S. 261).

${ }^{86}$ Zur Biographie Winther von Andernachs siehe W. Haberling in Klin. Wschr. 11 (1932) 1616-20. Zur Bio-Bibliographie s. E. Turner, in Gaz. hébd. méd. et chir. 28 (1881) 4.25-34, 441-8, 505-16; J.J. Höveler, Jahresbericht des Progymnasiums Andernach 1898/99 (hier ausführliche, aber nicht genaue Bibliographie).

${ }^{87}$ Claudii Galeni Pergameni De anatomicis administrationibus libri novem, De constitutione artis medicae ... Per Joan. Guinterium Andernacum latinitate recens donati, Basileae apud And. Cratandrum MDXXXI, praefatio, S. 2.

${ }^{88}$ Diels, Abh. Preuß. Akad. Wiss. 1912, S. 16.

${ }^{89} \mathrm{Zu}$ Hermann Crüser siehe Allgemeine Deutsche Bibliographie IV, 628-9.

${ }^{90}$ Mewaldt, Corpus Medicorum Graecorum V, 9, 1 (1914), praefatio, S. XX: «Ex hac editione principi profectae sunt versiones latinae comentarii primi ab Hermanno Cruserio Campensi, tertii ab Ioanne Guinterio Andernaco annis 1531 et 1533 editae.»

90a Claudii Galeni Pergameni Opera, iam recens versa ... Basileae ex aedibus And. Cratandri, Anno MDXXXI, S. 115v: Joachinus Martinius Gandavus Lectori ... 
reion die Aldina zusammen mit handschriftlichem Material ${ }^{91}$. Auch Augustinus GadalDINUs aus Modena, der bekannte Humanist und Herausgeber der ersten lateinischen GalenJuntina des Jahres 1541, zog, wenn immer möglich, griechische Handschriften für die lateinischen Übersetzungen galenischer Schriften heran ${ }^{92}$.

Der berühmteste Aldinenbesitzer des 16. Jahrhunderts war zweifellos Janus Cornarius aus Zwickau ${ }^{93}$, dessen Aldinenexemplare nach seinem Tode in die Universitätsbibliothek Jena übergegangen sind ${ }^{94}$. Am Rande der Blätter seiner Aldinenexemplare brachte Cornarius im Laufe der Jahre

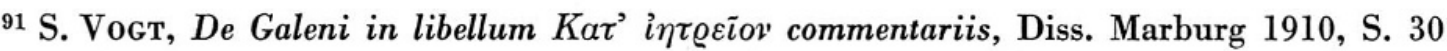
(= Vogt 1910).

92 Vgl. in erster Linie das Vorwort des Augustinus Gadaldinus aus Modena zur Juntina des Jahres 1541 (= Juntina I), wo er einen Rechenschaftsbericht über die Textgestaltung Galens gibt, die ihm anvertraut war. Dort stellt GADALDINUs auch seinen ärztlichen und humanistischen Mitarbeiterstab vor und berichtet über neues Handschriftenmaterial: Galeni Omnia Opera nunc primum in unum corpus redacta ... apud haeredes lucae antonij Juntae Florentini, Venetiis MDXLI, I. Band, fol. Ir: Augustinus Gadaldinus Mutinensis Medicinae Studiosis ... Primum id sibi faciendum censuerunt (nämlich die Familie Giunta), ut ex variis Italiae bibliothecis quotcumque potuissent, antiquissima manu scripta exemplaria conquirerent, quibuscum impressa haec collata, ad pristinum nitorem restituerentur: ne causa exemplarium irrepere amplius in hoc suum opus error aliquis posset. id quod etiam effectum est, atque omni ex parte fere successit: cum multa in illis pulcherrima scituque dignissima reperta fuerint, quae in impressis (gemeint ist die Editio aldina) desiderabantur. Deinde adhibitis nonullis doctis, et tam linguarum peritia quam medicina eruditissimis viris, libros omnes Galeni et qui nondum fuerant latinitate donati, in latinum vertendos: et qui latini quidem erant facti sed causa depravatorum, ut dixi, exemplarium male erant affecti, alios recognoscendos et castigandos, alios denuo transferendos curaverunt. Docti vero illi viri, eorum librorum, quos transferendos susceperunt, tum studio et diligentia, tum exemplarium illorum antiquorum auxilio, tralationem suam integriorem et dilucidiorem, quam in impressis codicibus graeca lectio (gemeint sind die Editio aldina und basileensis) circumferatur, nobis tradiderunt: id quod qui eam cum grecis conferre per ocium voluerint, perspicere facile poterunt ...»-Zu Gadaldinus und seiner Arbeit siehe noch M. Roth, Andreas Vesalius Bruxellensis, Berlin 1892, S. 109 ff., Anhang IX, S. 458 ff.; H. Cushing, A Bio-Bibliography of Andreas Vesalius, New York 1943, S. 63 ff.; F.R. DiEtz, Galeni de dissectione musculorum, Leipzig 1832, S. XVI; H. SснӧNE, Eine Streitschrift Galens gegen die empirischen Ärzte, in Sber. kgl. Preuß. Akad. Wiss. LI (1901) 1255-63; Vogt 1910, S. 29 ff.; K. Косн, Corpus Medicorum Graecorum V, 4, 2, praefatio, S. XXI.

${ }^{93}$ Zur Biographie des Cornarius s. O. Clemen, Janus Cornarius, in Neues Arch. Sächs. Gesch. Altertumskunde 33 (1912) 36-76; P. UhLIG, in Arch. Gesch. Med. 30 (1938) 301-6.

94 Tн. O. Achelis, in Neues Arch. Sächs. Gesch. Altertumskunde 34 (1913) 163-4; Сн. G. Gruner, Jani Cornarii conjecturae et emendationes Galenicae, Jena 1789, hat in diesem mir nicht zugänglichen Werk die Randnotizen des CorNarius, die in den Aldinaexemplaren der Jenenser Bibliothek standen, herausgegeben (siehe auch Anm. 95). 
zahlreiche Textverbesserungen an. Diese sind zum Teil konjekturaler Art, zum Teil stützen sie sich auf den Text alter lateinischer Übersetzungen (z.B. des Niccolò da Reggio) ${ }^{95}$ und möglicherweise stammen sie auch aus handschriftlichem Material. Wie aus einer Randnotiz der Cornarius-Aldina (Vol. I, fol. 96v) hervorgeht, übersetzte Cornarius aus der Aldina die galenische Schrift peri metras anatomes ${ }^{96}$. In den Händen des Cornarius, der zahlreiche galenische Schriften ins Lateinische übertrug und die Opera omnia latina Galens, die 1549 in Basel bei Froben erschienen, besorgte, wurde die Aldina zu einem besonders wirkungsvollen Arbeitsinstrument ${ }^{96 a}$.

Als Cornarius im Jahre 1528 nach Basel kam und hier in der Officin der Froben die Aldinen des Galen, Hippokrates und Paulus von Ägina zu Gesicht bekam, wurde ihm diese Begegnung mit den griechischen Ärzten zu einem Erlebnis, das seine spätere Arbeitsrichtung entscheidend bestimmte. Rund zwanzig Jahre später stellte er dazu fest ${ }^{97}:$ «... tum toto pectore ad Hippocratem Graecum ac Galenum, itemque Paulum me contuli, paulo ante Venetiis ex Aldi itidem officina allatos ... » Bis zu jener Zeit, so schrieb Cornarius weiter ${ }^{98}$, herrschte ein großer Mangel an brauchbaren medizinischen Texten «... magna erat bonorum et professorum, et librorum penuria ...» Es gab nur einige wenige lateinische Übersetzungen einzelner galenischer und hippokratischer Werke, die Leoniceno und Cop gemacht hatten ${ }^{99}$. Aber in ihrer griechischen Ursprache, bemerkte Cornarius, waren die griechischen Ärzte noch nicht erschienen. Einzig die Therapeutica Galens hätte er bei einem Freunde in ihrer griechischen Fassung eingesehen: «Verum in medicina nihil Hippocratis

${ }^{95}$ Die umfassendste Textbearbeitung des Corpus Galenicum im 16. Jahrhundert hat wohl Cornarius geleistet. In diesem Urteil stimmen sowohl sein Zeitgenosse, Conrad GessNER, der ebenfalls ein ausgezeichneter Kenner Galens war, und die modernen Editoren Galens überein. Vgl. dazu: Wenkebach 1917, S. 8 ff.; Noll 1915, S. XXVI ff.; J. Mewaldt, Corpus Medicorum Graecorum V, 9, 1, praefatio, S. XXI ff.; G. Helmreich, Ed. Gal. de usu part., Lipsiae 1907, praefatio, S. XV; K. KocH, Corpus Medicorum Graecorum V, 4, 2 (1923) praefatio, S. XXII-XXIV, und G. HeLMreICH, ibid., praefatio, S. XLI, XLVII.

${ }_{96}$ Wenkebach 1917, S. 9. Zur galenischen Schrift De utilitate respirationis bemerkte Cornarius in einer Randnotiz im 3. Bande seiner Galenaldina: "Converti ego Janus Cornarius Medicus. Anno MDXXXIII Northusii. Mense Septembri», siehe R. Noll 1915, S. XXVII.

96 a Ein weiterer Aldinenbesitzer war der berühmte Humanist JosePH JuSTus SCALIGER, siehe G. Helmreich, Corpus Medicorum Graecorum V, 9, 1, 1914, praefatio, S. XXXVIII. Zu J. J. Scaliger vgl. J. Bernays, Joseph Justus Scaliger, Berlin 1855.

${ }^{97}$ Hippocratis Coi Medicorum omnium longe principis opera quae ad nos extant omnia per Janum Cornarium Medicum physicum latina lingua conscripta, Froben, Basileae MDXLVI (= Cornarius, Hipp. 1546), praefatio, fol. 1v.

${ }^{98}$ Cornarius, Hipp. 1546, praefatio, fol. $1 \mathrm{r}$.

${ }^{99}$ Cornarius, Hipp. 1546, praefatio, fol. $1 \mathrm{v}$. 
ac Galeni ipsorum lingua habebatur, praeter Hippocratis aphorismos, quos Philippus Melanchthon mihi communicaverat, et unam Galeni methodum ... ${ }^{100}$.

Cornarius las sich anhand der Aldina und der lateinischen Galen-Übersetzungen so sehr in diesen Autor ein, daß er die zweite Froben-Ausgabe der lateinischen Gesamtwerke Galens (Basel 1549) besorgte. Er umschrieb seine Galen-Lektüre mit folgenden Worten ${ }^{101}$ : «... tum perlecta denuo tota Galeni graeca ac latina editione, eo studio ut totum aliquando editurus sim Galenum ...» Ein so genauer Kenner des galenischen Corpus wie Conrad Geßner schrieb nach dem Tode des Cornarius in den Prolegomena zu der dritten Galenausgabe Frobens (Basel 1562), daß Cornarius die Arbeit zu einer brauchbareren Ausgabe des griechischen Galen-Textes abgeschlossen hätte. Einzig der Drucker zum griechischen Galen hätte sich nicht finden lassen. Nun, da Cornarius verschieden sei, entschwinde diese Hoffnung: «... atque utinam supervixisset doctissimus utriusque linguae Cornarius, qui omnia a se emendata, iamque editioni, si quis typographorum suscipere voluisset, parata habebat, ut scribit ipse ... ${ }^{102}$

Zusammenfassend können wir sagen: Die eigentliche «medizinische» Bedeutung der Aldina liegt darin, daß sie gleichsam als eine riesige, bequem zugängliche Handschrift das Gesamtopus Galens den Übersetzern darbot. Da die lateinische Sprache auch im 16. Jahrhundert die Fachsprache der Medizin blieb ${ }^{103}$, lautete das allgemeine Programm der Philologenärzte «latinitate donare», die Übertragung der griechischen medizinischen Texte in die lateinische Sprache. Bei der Ausführung dieses Vorhabens erfüllte die Aldina, wie wir gesehen haben, eine wichtige Funktion. Die Galen-Juntina I, welche im Jahre 1541 in Venedig erschien, ist als erstes lateinisches Gesamtwerk Galens zu betrachten, das vollständig nach den im 16. Jahrhundert sich entwickelnden ärztlich-humanistischen Grundsätzen und Methoden durchgearbeitet ist. Zahlreiche, von nordischen und

100 Cornarius, Hipp. 1546, praefatio, fol. $1 \mathrm{v}$.

101 Cornarius, Hipp. 1546, praefatio, fol. 3 r.

102 Cl. Galeni Pergameni omnia, quae extant, in Latinum sermonem conversa ... ex III. officin. Frobenianae Editione MDLXII, Prolegomena (Gesneri), Emblema I.

${ }^{103}$ Vgl. dazu die ausführliche Darstellung bei L. OLScHKI, Bildung und Wissenschaft im Zeitalter der Renaissance in Italien (=2. Bd. von: Gesch. der neusprachlichen wissenschaftlichen Literatur) Leipzig/Firenze/Rom/Genève 1922, S. 64-111 (= Das Latein als wissenschaftliche Sprache). - CoRNarIUs betonte, es wäre höchst wünschenswert, wenn die griechischen Ärzte in ihrer eigenen Sprache studiert würden. Solange jedoch die Kenntnis des Griechischen nicht Allgemeingut sei, müsse man, um die griechischen medizinischen Texte an die Ärzte heranzutragen, den Umweg über die lateinische Sprache einschlagen. "Quin et ego semper ita sensi, melius esse quosvis scriptores in sua lingua, qua ipsi scripserunt legere, quam optime etiam in aliam translatos. Sed quid facient hi qui Graecum non intelligunt? ... Quamdiu vero expectandum nobis est hoc saeculum, in quo medicinae studiosi ex aequo omnes ad legendum ac intelligendum Hippocratem Graecum sufficient?» Cornarius, Hipp. 1546, fol. 4r. 
Der Übergang der Galen-Tradition vom späteren Mittelalter zur Neuzeit

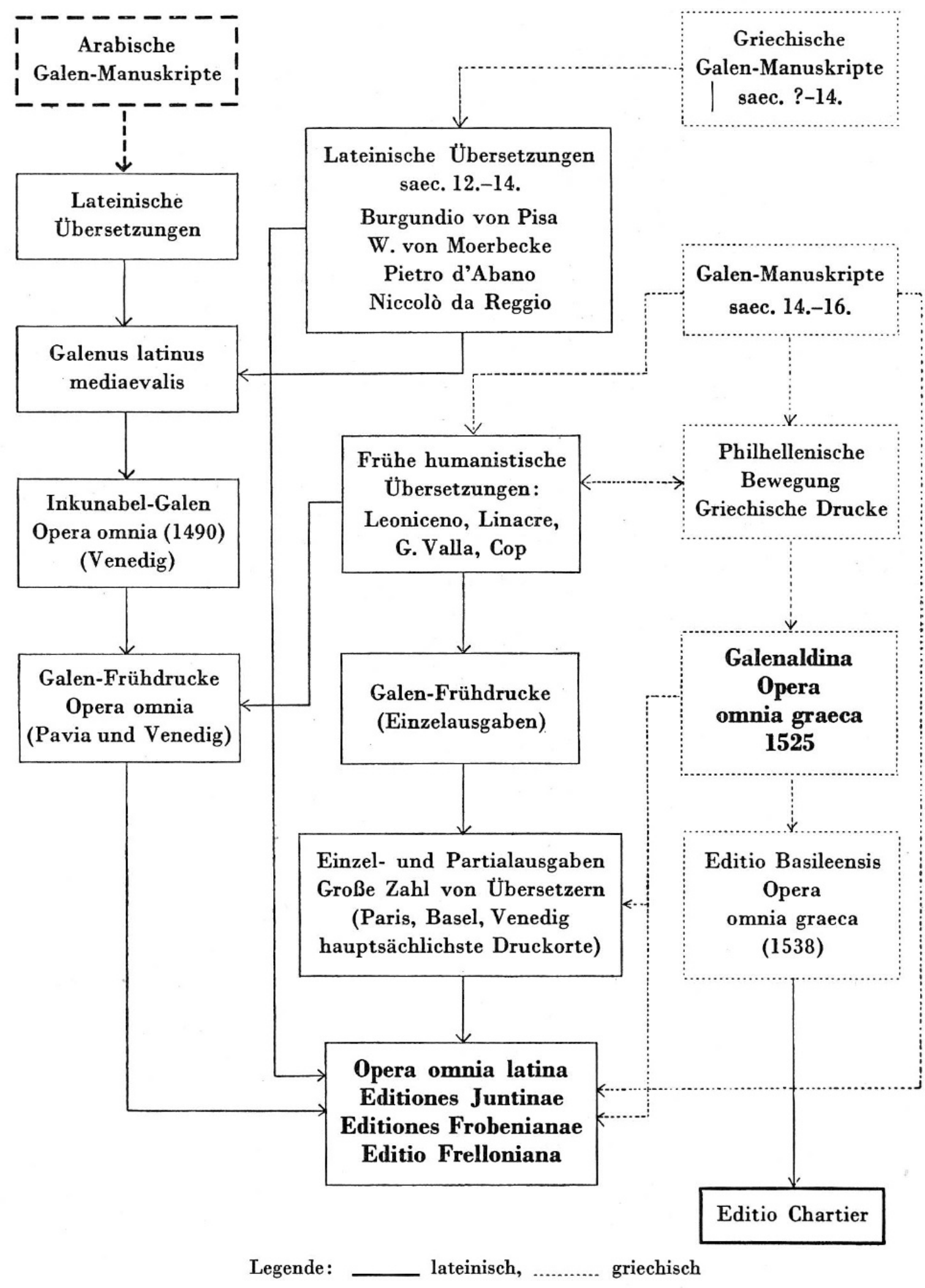


italienischen Humanisten und Humanistenärzten verfertigten Galen-Übersetzungen - und ein Teil derselben hatte die Aldina zur Vorlage - wurden hier in das Gesamtopus Galens aufgenommen, nachdem einige zuvor anhand von neugefundenen griechischen Handschriften nochmals überarbeitet oder auch neu übersetzt worden waren. Erst mit den zahlreichen, vor allem aus den Druckwerkstätten der Junta und Froben herauskommenden lateinischen Ausgaben der Opera omnia Galens, die eine systematische Gliederung der galenischen Schriften nach ärztlichen Gesichtspunkten ${ }^{104}$ aufwiesen, die die pseudogalenischen Werke von den authentischen schieden und die vor allem einen ausführlichen Index zum Gesamtwerk besaßen, wurde Galen zu einem bequem benutzbaren Autoren, der sich neben dem Canon des Avicenna behaupten konnte. Ein wichtiges Glied in der Entwicklungskette, die zu diesem Ergebnis führte, bildete die Galenaldina. Daneben ist die Galenaldina eines der eindrücklichsten Zeugnisse der philhellenischen Richtung innerhalb der Renaissancemedizin.

${ }^{104}$ Die medizinische Systematik des Corpus Galenicum für die Juntina I (1541) übernahm Giovanni Battista Montano. Vgl, seine Widmung im 1. Bande dieses Werkes: «Ioannes Baptista Montanus Physicus Veronensis Lucae Antonio Juntae S.»; ebenfalls abgedruckt im 1. Bande der Galen-Ausgabe Frobens (Basel 1542). 